\title{
Intraoperative Radiation Therapy (INTRABEAM) Experience at the Mastology Unit Leopoldo Aguerrevere Clinic
}

\author{
Gerardo Hernández Muñoz*, Ricardo Paredes Hany, Alecia Cosson, Claudia Gonzalez, \\ Juan Hernández Rasquií, Ivo Rodriguez, Jose Ghaleb, Elizabeth Gonzalez, \\ Maria Mercedes Benitez, Wendy Hurtado, Nestor Sanchez, Consuelo Figuera \\ Unidad Mastologia, Caras, Venezuela \\ Email: drgerher@cantv.net
}

Received 25 July 2015; accepted 25 September 2015; published 28 September 2015

Copyright (C) 2015 by authors and Scientific Research Publishing Inc.

This work is licensed under the Creative Commons Attribution International License (CC BY). http://creativecommons.org/licenses/by/4.0/

(c) (i) Open Access

\begin{abstract}
Introduction: External radiation therapy has been the fundamental pillar when treating breast cancer. Partial radiation therapy and intraoperative radiation treatment have created modifications that allow the irradiation of the breast to be performed at the surgical act delivering a single large fraction or a "boost" dose directly at the tumor bed. We will discuss patients treated with INTRABEAM (Carl Zeiss Surgical Oberkochen, Germany) at the "Mastology Unit at Leopoldo Aguerrevere Clinic". Materials and Methods: The selection of patients is crucial for the success of the treatment, same protocol of treatment has been applied to every patient at the surgical act. Since September 2013 until February 2015, we have treated a total of 148 patients with the INTRABEAM unit, we will discuss the 114 patients treated by the team at the "Mastology Unit at Leopoldo Aguerrevere Clinic" with ages between 31 and 87 years in which $46 \%$ were single treatments and $\mathbf{5 4 \%}$ were treated as a "boost" for external radiation therapy. Results: The procedure has been well tolerated with only a $17 \%$ of transient fibrosis and a $12 \%$ of seromas. We have had none mayor complications like dehiscence of the wound or necrosis of the borders. Conclusion: With this preliminary presentation, we would like to demonstrate that the technique and protocol used at our mastology unit with the intraoperative radiation treatment is safe and has many advantages to the patients including better comfort, cost-effective and with results comparable to external radiotherapy.
\end{abstract}

Keywords

Radiotherapy, Intraoperative Radiotherapy, Breast Cancer, Radiation Treatment, INTRABEAM

${ }^{*}$ Corresponding author.

How to cite this paper: Muñoz, G.H., et al. (2015) Intraoperative Radiation Therapy (INTRABEAM) Experience at the Mastology Unit Leopoldo Aguerrevere Clinic. Journal of Cancer Therapy, 6, 932-942. http://dx.doi.org/10.4236/jct.2015.610101 


\section{Introduction}

External radiotherapy applied to the whole mammary gland has been one of the fundamental pillars for conservative breast cancer treatment [1], with a significant decrease in local recurrence and mortality [2] [3]. Omission of radiotherapy even in well selected patients increases risk of recurrence [4].

Intra-Operative Radiation Treatment (IORT) can substitute 1 week of external radiotherapy with a Boost dose or the complete 6 weeks of radiotherapy with a single treatment session with an equivalent dose during surgery. Recurrence rate (80\% - 90\%) with or without radiotherapy is localized on the tumor bed or adjacent to it, independently of multicentre foci, therefore it suggests that the administration of the dose directly to the tumor bed would achieve a local tumor control comparable to the external radiotherapy to the whole breast in well selected patients [5]. Further than the evident advantages, it facilitates treatment for patients living far away from radiotherapy units, there is no need for daily consults and complements the lack of external radiotherapy equipments.

Whole irradiation to the breast has secondary side effects such as dermatitis, hyperpigmentation, cutaneous atrophy, osteoradionecrosis, pneumonitis and cardiac toxicity, this last one for left breast radiant treatment. IORT allows direct local radiation dose delivery to the tumor bed and decreases exposure to healthy tissues and adjacent organs. The present paper wishes to introduce the application technique used with the INTRABEAM by the "Mastology Unit at Leopoldo Aguerrevere Clinic".

\section{Methods}

Since September 2013 we have used the INTRABEAM unit (Carl Zeiss Surgical Oberkochen, Germany) (Figure 1) for IORT, it is a mobile miniaturized photon radiosurgery system that accelerates electrons through a $10 \mathrm{~cm}$ drift tube onto a gold target and generates low energy $\mathrm{X}$ rays $(\sim 50 \mathrm{kV})$ that are emitted isotopically (Figure 2).

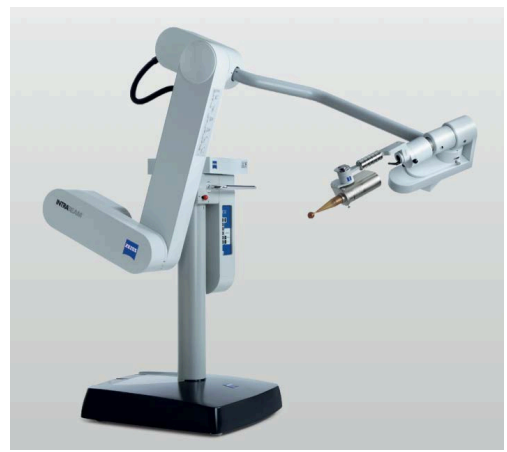

Figure 1. Intrabeam unit.

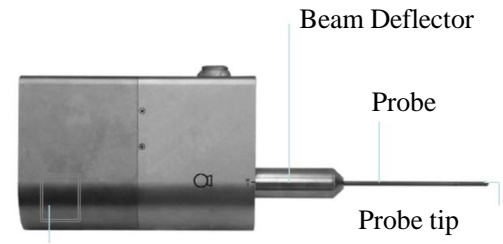

Internal Radiation Monitor

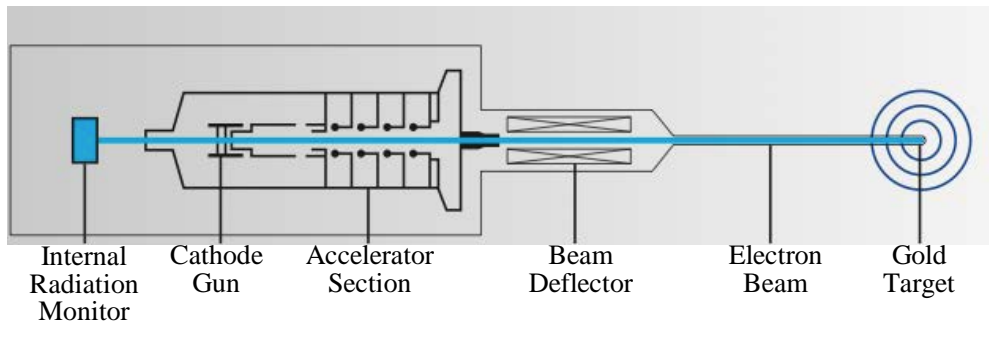

Figure 2. X-ray generator. 
The tip of the generator becomes a radiation source that undergoes a quality assurance previous to each treatment that involves checks of the probe straightness, adjustment of the bending current, verifying the symmetry (isotropy) of the dose distribution and the dose output.

The selection of patients is crucial for the success of the treatment. Our selection protocol for single dose IORT consists of the following requisites (Table 1 ).

Patients that do not fulfill the requisites included in Table 1. Classify for a Boost dose treatment.

A partial oncological mastectomy (lumpectomy) is performed with adequate margins, the sample is sent to the pathology anatomy laboratory to verify that the margins are disease free and sentinel node biopsy is performed. In subclinical lesions, tumor is localized with placement of Iodine_125 seed (ROLL) or wire, the sample is then sent to the radiology department to confirm resection of the tumor.

After verifying margins with pathology, resecting more if necessary, undermining the edges at tumor bed cavity is performed (Figure 3); purse-string suture is applied and tested to ensure complete coverage around the applicator (Figure 4).

A spherical applicator with the adequate diameter is selected and attached to the source, it is inserted into the surgical cavity to fill the area of the tumor bed and deliver a homogeneous dose to all margins. Applicators sizes range from $1.5 \mathrm{~cm}$ to $5 \mathrm{~cm}$ with $0.5 \mathrm{~cm}$ increment (Figure 5). Skin edges are separated from the applicator with a cheek retractor, wet gauss or stay sutures (Figure 6).

Tungsten-filled drapes are placed on the chest of the patient for shielding. Low energy $\mathrm{X}$ rays interact with soft tissue delivering their complete energy resulting in a quick attenuation of exposure rate that allows treatment to be performed in a standard operating room with no additional shielding required (Figure 7).

Time of treatment is individually calculated depending on prescribed dose, cavity size and by consequence the diameter of the applicator (each applicator has an attenuation transfer function that takes into account attenuation and scatter due to the size). For an example of a single dose treatment prescription with a $3.5 \mathrm{~cm}$ diameter applicator refer to Table 2 (Graphic 1).

For Boost treatments the dose prescribed is of $20 \mathrm{~Gy}$ to the surface of the tumor bed and $45 \mathrm{~Gy}$ in 28 sessions of EBRT to the whole breast (Table 3, Graphic 2).

Treatment is delivered, INTRABEAM is removed from the patient, and titanium clips are located at the tumor bed and axilla. Tumor bed is reconstructed, the wound is closed which completes the procedure.

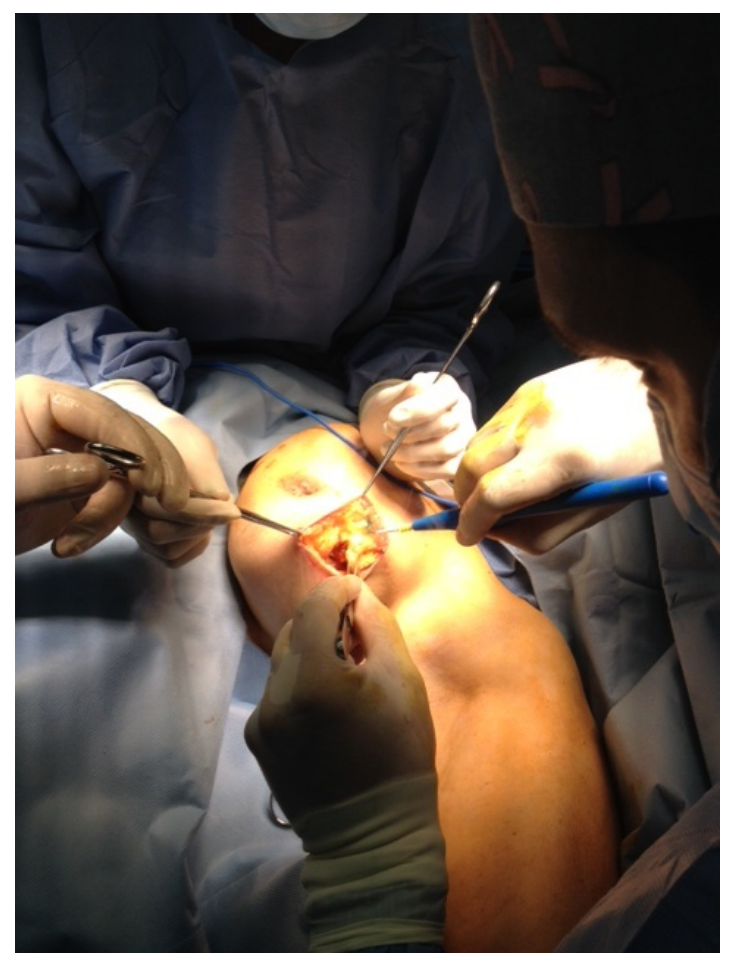

Figure 3. Undermining the edges. 


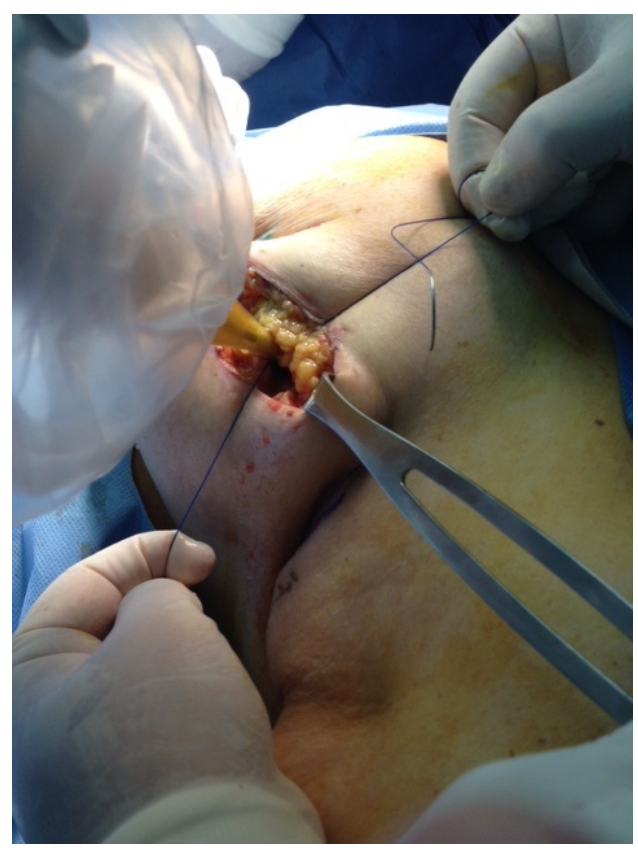

Figure 4. Testing applicator.

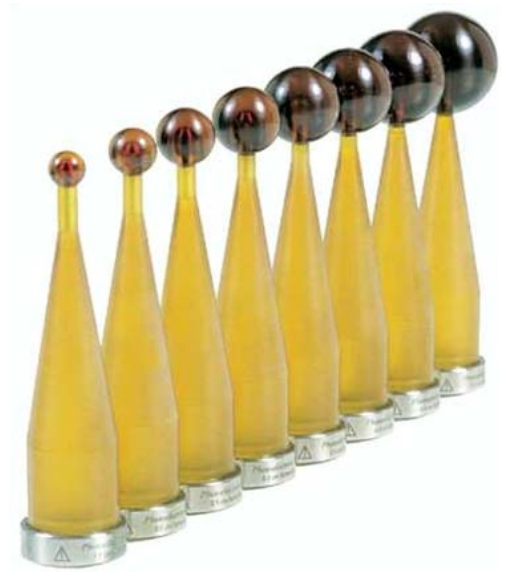

Figure 5. Applicators.

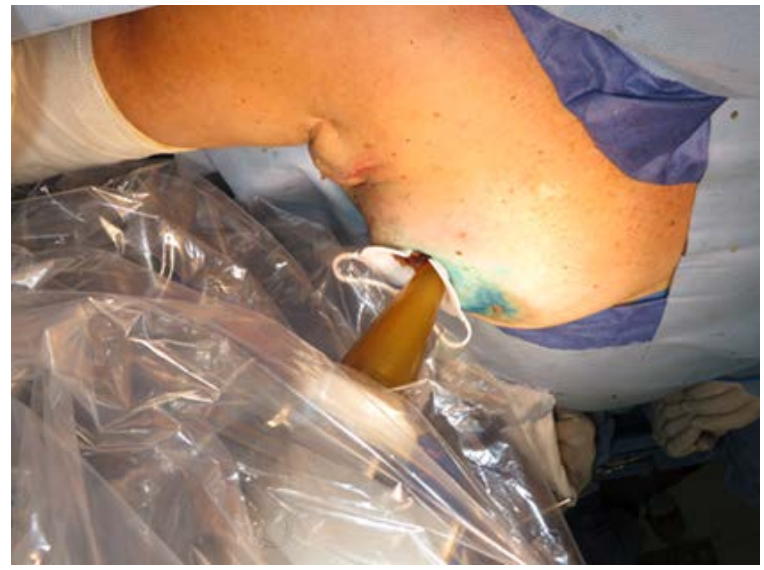

Figure 6. Applicator at tumor bed. 


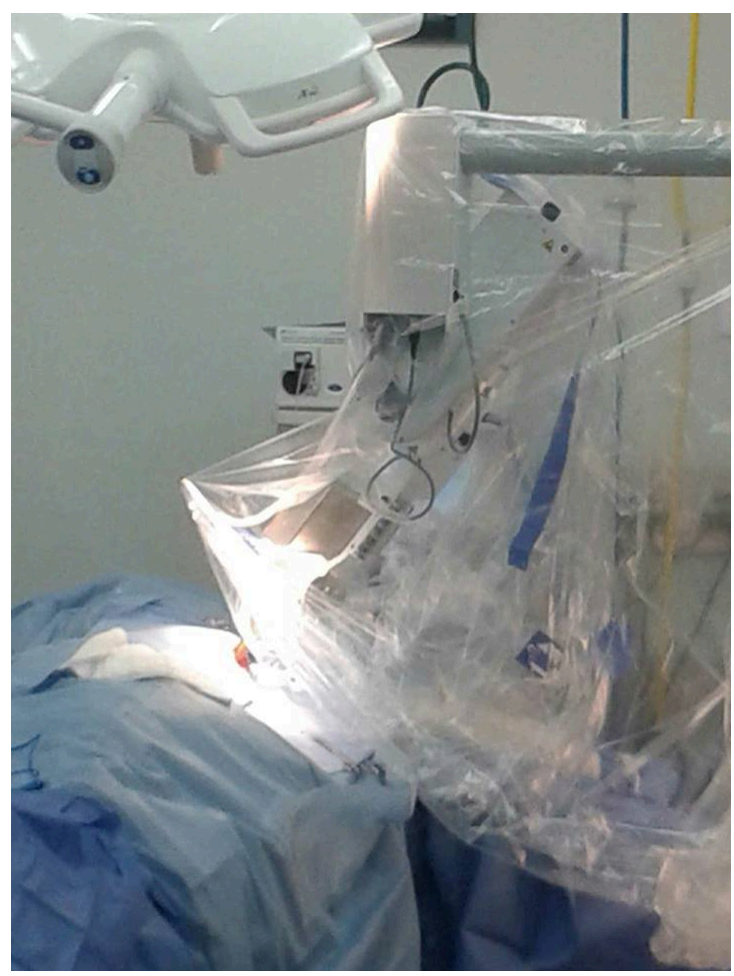

Figure 7. INTRABEAM and Tungsten-filled drapes placed on patient.

Table 1. Requisites for single dose IORT.

\begin{tabular}{cc}
\hline Age & $>45$ \\
\hline Histologic type & Ductal infiltrating \\
Sentinel node & Negative \\
Hormonal receptor & at least one positive \\
Herb2-neu & Negative \\
Tumor size & $<2 \mathrm{~cm}$ \\
Margins & Negative \\
Linfovascular infiltration & None \\
Intraductal component & $<25 \%$ \\
\hline
\end{tabular}

Table 2. Prescribed single dose (for $3.5 \mathrm{~cm}$ applicator).

\begin{tabular}{cc|}
\hline Depth (mm) & Dose (Gy) \\
\hline 0 & 28.2 \\
2 & 20 \\
5 & 12.8 \\
10 & 6.9 \\
15 & 4.2 \\
20 & 2.6 \\
\hline
\end{tabular}


Table 3. Prescribed boost dose (for $3.5 \mathrm{~cm}$ applicator).

\begin{tabular}{cc}
\hline Depth (mm) & Dose (Gy) \\
\hline 0 & 20 \\
2 & 14 \\
5 & 9.1 \\
10 & 5 \\
15 & 2.9 \\
20 & 1.9 \\
\hline
\end{tabular}

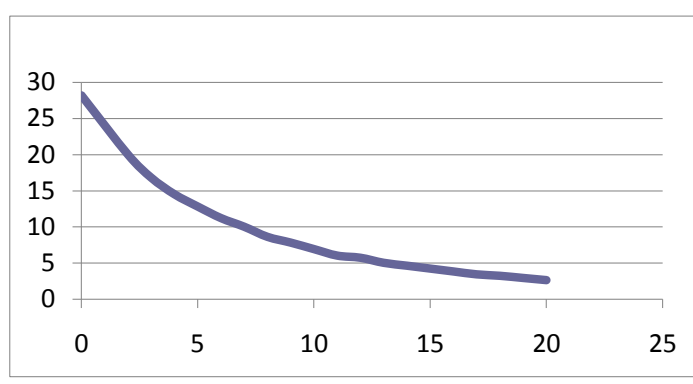

Graphic 1. Depth Dose curve for 20 Gy at $2 \mathrm{~mm}$ depth for a $3.5 \mathrm{~cm}$ applicator.

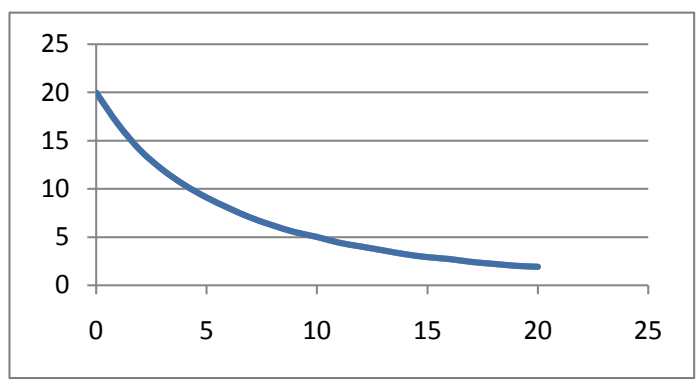

Graphic 2. Depth dose curve for $20 \mathrm{~Gy}$ at $0 \mathrm{~mm}$ depth for a $3.5 \mathrm{~cm}$ applicator.

\section{Material}

We have treated 114 patients, with ages between 31 and 87 (Table 4).

There were 53 single dose treatments and 61 as boost for EBRT (Table 5)

For single dose treatments ages were between 46 and 87 years of age (Table 6).

And for Boost treatments ages were between 30 and 85 years (Table 7).

\section{Results}

We cannot establish a statistically significant result in life spam since there hasn't been enough time for follow ups. The most relevant secondary effects have been $12 \%$ seromas and $17 \%$ of light fibrosis (Table 8 ). No necrosis at the borders or dehiscence of the wound.

No complications on patients with prosthesis in single dose treatments. Esthetics results have been excellent (Figure 8, Figure 9), patients response to satisfaction and quality of life have been very positive, as shown by an inquiry made to a group of patients treated with external radiotherapy or INTRABEAM that concluded: "factors as tattoo discomfort, pain on the breast or wound, skin burn, pain in the arm and difficulties returning to their daily routine or jobs are almost un-existent to patients treated with INTRABEAM in comparison with external radiation patients" [6].

There has been no need of reoperation due to compromised margins at the final biopsy. 
Table 4. Age range of patients treated with INTRABEAM.

\begin{tabular}{cccc}
\hline Total Treatments & & \\
\hline Age & Number & Percent (\%) \\
\hline $30-40$ & 6 & 5.26 \\
$41-45$ & 13 & 11.4 \\
$46-50$ & 18 & 15.79 \\
$51-55$ & 12 & 10.53 \\
$56-60$ & 15 & 13.16 \\
$61-65$ & 19 & 16.67 \\
$66-70$ & 9 & 7.89 \\
$71-75$ & 14 & 12.28 \\
$76-80$ & 5 & 4.39 \\
$>80$ & 3 & 2.63 \\
Total & $\mathbf{1 1 4}$ & \\
Age average & $\mathbf{5 8}$ & \\
\hline
\end{tabular}

Table 5. Percentage of patients treated with single dose or boost.

\begin{tabular}{ccc}
\hline Type of Treatment & Number & Percent (\%) \\
\hline Single treatment & 53 & 46.5 \\
Boost treatment & 61 & 53.5 \\
Total & $\mathbf{1 1 4}$ & \\
\hline
\end{tabular}

Table 6. Ages of patients treated with single dose.

\begin{tabular}{|c|c|c|}
\hline Single Dose Treatment & & \\
\hline Age & Number & Percent (\%) \\
\hline $30-40$ & 0 & 0 \\
\hline $41-45$ & 0 & 0 \\
\hline $46-50$ & 10 & 18.9 \\
\hline $51-55$ & 6 & 11.3 \\
\hline $56-60$ & 10 & 18.9 \\
\hline $61-65$ & 11 & 20.7 \\
\hline $66-70$ & 5 & 9.4 \\
\hline $71-75$ & 7 & 13.2 \\
\hline $76-80$ & 2 & 3.8 \\
\hline$>80$ & 2 & 3.8 \\
\hline Total & 53 & \\
\hline Age average & 58 & \\
\hline
\end{tabular}


Table 7. Ages of patients treated with boost dose.

\begin{tabular}{cccc}
\hline Single Dose Treatment & & \\
\hline Age & Number & Percent (\%) \\
\hline $30-40$ & 6 & 9.8 \\
$41-45$ & 13 & 21.3 \\
$46-50$ & 8 & 13.1 \\
$51-55$ & 6 & 9.8 \\
$56-60$ & 5 & 8.2 \\
$61-65$ & 8 & 13.1 \\
$66-70$ & 4 & 6.6 \\
$71-75$ & 7 & 11.5 \\
$76-80$ & 3 & 4.9 \\
$>80$ & 1 & 1.7 \\
Total & $\mathbf{6 1}$ & \\
Age average & $\mathbf{5 8}$ & \\
\hline
\end{tabular}

Table 8. Complications.

\begin{tabular}{ccc}
\hline Type of Complication & Number of patients & Percentage \\
\hline Seroma & 14 & $12 \%$ \\
Fibrosis & 19 & $17 \%$ \\
\hline
\end{tabular}

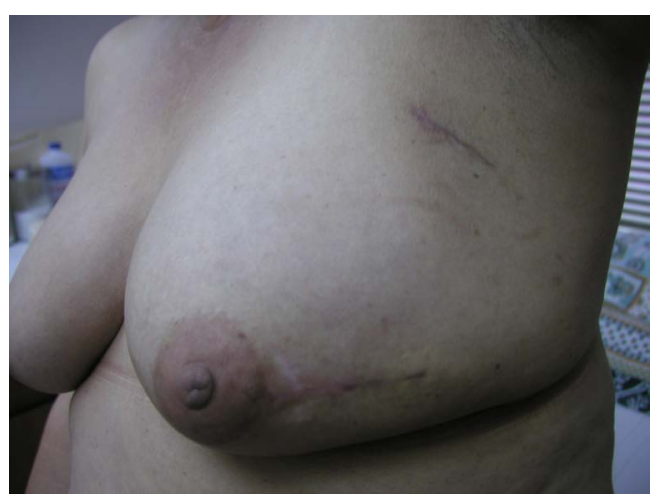

Figure 8. Photo of patient esthetics follow up.



Figure 9. Photo of esthetics follow up. 


\section{Discussion}

In the last decade, there have been dramatic changes on the management for local breast cancer, from radical surgery to more conservative surgical therapies with use of postoperative radiotherapy, which showed that survival rates with conservative surgery followed by radiotherapy were equivalent to more radical surgical procedures [7]-[9].

Routine whole-breast radiotherapy comprises of 45 - 50 Gy in daily fractions for 5 weeks, the additional application of an external boost of 10 - 16 Gy to the tumor bed leads to excellent local tumor control with local recurrence rates around 6\% after a median of 10 year follow up. However, in view of the low and focal recurrence rates, the concept of accelerated partial-breast irradiation has gained widespread interest with various methods [10] [11]. This fact has lead to new approaches focusing the radiation therapy to just the portion of the breast considered to be high risk of developing local recurrence.

Intraoperative radiotherapy is one method that offers the advantage of excellent delineation of the tumor bed under visual control, very good dose-homogeneity and high sparing of normal tissue [12] [13], it is delivered before the tumor cells had time to proliferate and at the moment of surgery the tissue has better vascularity and aerobic metabolism which makes it more radiosensitive that it would be after several weeks of surgery when vascular alterations phenomena's and fibrosis occur diminishing oxygen availability in the area [14]. Targeted radiotherapy significantly diminishes cardiac and lung irradiation lowering risks of late sequel.

Histopathological studies on selected women for conservative surgery of the breast have demonstrated that it's improbable that the microscopic extension of the malignant cells reaches more than $1 \mathrm{~cm}$ [15] therefore local recurrence very probably develops from the cells that surround the primary tumor and not from additional cancer foci, this suggests that the primary target that requires adjuvant treatment with radiotherapy following a lumpectomy (with negative margins) it's probably limited by a $2 \mathrm{~cm}$ area around the borders of the cavity [16][18]. Taking that into account to avoid risks of recurrence for single dose treatments we deliver a dose of 20 Gy prescribed at $2 \mathrm{~mm}$, that for instance for a $3.5 \mathrm{~cm}$ diameter applicator will deliver a $6.9 \mathrm{~Gy}$ at a depth of $1 \mathrm{~cm}$, plus the margins given at the lumpectomy it broadens the area of treatment to include the volume desired.

In selected patients, these methods result in a reduction in the volumes treated and duration of radiation without a reduction in survival. Factors for local recurrence were established by proposing a model starting with patients treated in nine randomized trials. The most significant factors were age $\leq 40$ (45) years (hazard ratio (HR) 2.03) margin invasion (2.19), positive RHs (0.73) and grade -3 tumors (HR 1.55) [19]. Vaidya et al. showed the absence of a significant difference in terms of focal recurrence $\leq 4$ years in 2232 randomized patients between external radiotherapy and intraoperative radiotherapy with $50 \mathrm{kV}$ intrabeam photons [20]. Other methods of accelerated partial-breast irradiation using brachytherapy and external radiotherapy for early breast cancer (ELIOT) have confirmed the safety of this type of treatment [21] [22]. In the G3S cohort, survival without locoregional recurrence at 5 years was $98 \%$ and $97.6 \%$ respectively, for patients eligible for TARGIT according to the criteria of the IORT and TARGIT-A trials. In the IPC cohort, survival without local recurrence at 5 years was $98.6 \%$ and $96.6 \%$ respectively for the two groups. Therefore we would expect comparable values for local recurrence if the patients had been treated effectively by TARGIT.

Although significant, the difference in 5 years locoregional recurrence between T1E and T1nE (97.6\% versus 97\%) was small in absolute terms (0.6\%). However, the number of patients still exposed to the risk at 5 years is acceptable $(1921 / 4031=46.6 \%$ and $1800 / 3540=50.8 \%$, respectively, in T1E and T1nE subgroups).

Her2 overexpression has been reported to be an aggravating factor for local recurrence, though its value as a factor independent of other criteria [23].

In 2014 Vaidya et al., reported 5 years results for local recurrence and the first analysis of overall survival. Randomization occurred either before lumpectomy (pre-pathology stratum, TARGIT concurrent with lumpectomy) or after lumpectomy (post-pathology stratum, TARGIT given subsequently by reopening the wound). Patients in the TARGIT group received supplemental EBRT (excluding a boost) if unforeseen adverse features were detected on final pathology. The primary outcome was absolute difference in local recurrence in the conserved breast, with pre-specified non-inferiority margin of $2.5 \%$ at 5 years. Their findings were that supplemental EBRT after TARGIT was necessary in $15.2 \%$ of patients who received TARGIT (21.6\% pre-pathology, $3.6 \%$ post-pathology). The 5 year risk for local recurrence in the conserved breast was 3.3\% (95\%) for TARGIT versus $1.3 \%$ for EBRT. TARGIT concurrently with lumpectomy (pre-pathology, $\mathrm{n}=2298$ ) had much the same results as EBRT 2.1\% versus 1.1\%. With delayed TARGIT (post-pathology, $n=1153$ ) the between group differ- 
ence was larger than 2.5\% (TARGIT 5.4\% vs EBRT 1.7\%). Overall, breast cancer mortality was much the same between groups ( $2.6 \%$ for TARGIT vs $1.9 \%$ for EBRT) but there were significantly fewer non breast cancer deaths with TARGIT (1.4\% vs 3.5\%), attributable to fewer deaths from cardiovascular causes and other cancers. Overall mortality was $3.9 \%$ for TARGIT versus $5.3 \%$ for EBRT. Wound related complications were much the same between the groups, but there were significantly fewer grade 3 or 4 radiotherapy related complications with TARGIT than with EBRT [24].

In accordance with the findings mentioned above it is important to emphasize that is it crucial that the selection of patients must follow the eligibility criteria and favor the pre-pathology approach over the delayed approach.

The high percentage of boost treatments in our experience 53.5\% shows that there is still much to be done to increase the early diagnosis.

It is also important to mention the potential economic incentive of this method is undeniable because intraoperative radiotherapy provides the best possibility for treatment limited to a single day in an outpatient setting. A recent study of 59,396 patients showed an increase in the use of partial accelerated irradiation of the breast from $3.4 \%$ in 2003 to $12.8 \%$ in 2008 [25].

\section{References}

[1] Veronesi, U., Banfi, A., Saccozzi, R., Salvadori, B., Zucali, R., Uslenghi, C., et al. (1977) Conservative Treatment of Breast Cancer. Cancer, 39, 2822-2826. http://dx.doi.org/10.1002/1097-0142(197706)39:6<2822::AID-CNCR2820390670>3.0.CO;2-\#

[2] Veronesi, U., Saccozzi, R., Del Vecchio, M., Banfi, A., Clemente, C., De Lena, M., et al. (1981) Comparing Radical Mastectomy with Quadrantectomy, Axillary Dissection and Radiotherapy in Patients with Small Cancers of the Breast. New England Journal of Medicine, 305, 6-11. http://dx.doi.org/10.1056/NEJM198107023050102

[3] Fisher, B., Bauer, M., Margolese, R., Poisson, R., Pilch, Y., Redmond, C., et al. (1985) Five Years Results of a Randomized Trial Comparing Total Mastectomy and Segmental Mastectomy with or without Radiation in the Treatment of Breast Cancer. New England Journal of Medicine, 312, 665-663. http://dx.doi.org/10.1056/NEJM198503143121101

[4] Early Breast Cancer Trialists’ Collaborative Group (EBCTCG), Darby, S., McGale, P., Correa, C., Taylor, C., Arriagada, R., et al. (2011) Effect of Radiotherapy after Breast-Conserving Surgery on 10-Year Recurrence and 15-Year Breast Cancer Death: Meta-Analysis of Individual Patient Data for 10,801 Women in 17 Randomized Trials. Lancet, 378, 1707-1716. http://dx.doi.org/10.1016/S0140-6736(11)61629-2

[5] Baum, M., Vaidya, J.S. and Mittra, I. (1997) Multicentricity and Recurrence of Breast Cancer. Lancet, 349, 208. http://dx.doi.org/10.1016/S0140-6736(05)60950-6

[6] Chirico, S., Paredes, R. and Soto, A. (2014) Trabajo de tesis de $5^{\text {to }}$ año de bachillerato. Colegio Emil Friedman, Caracas.

[7] Fisher, B., Anderson, S., Bryant, J., Margolese, R.G., Deutsch, M., Fisher, E.R., et al. (2002) Twenty-Year Follow-Up of a Randomized Trial Comparing Total Mastectomy, Lumpectomy and Lumpectomy plus Irradiation for the Treatment of Invasive Breast Cancer. New England Journal of Medicine, 347, 1233-1234. http://dx.doi.org/10.1056/NEJMoa022152

[8] Veronesi, U., Marubini, E., Mariani, L., Galimberti, V., Luini, A., Veronesi, P.L., et al. (2001) Radiotherapy after Breats-Conserving Surgery in Small Breast Carcinoma: Long Term Results of a Randomizer Trial. Annals of Oncology, 12, 997-1003. http://dx.doi.org/10.1023/A:1011136326943

[9] (1995) Effects of Radiotherapy and Surgery in Early Breast Cancer. An Overview of the Randomized Trials. Early Breast Cancer Trialists' Collaborative Group. New England Journal of Medicine, 333, 1444-1455.

[10] Clarke, M., Collins, R., Darby, S., Davies, C., Elphinstone, P., Evans, V., et al. (2005) Effects of Radiotherapy and of Differences in the Extent of Surgery for Early Breast Cancer on Local Recurrence a 15-Years Survival: An Overview of the Randomized Trials. Lancet, 366, 2087-2106. http://dx.doi.org/10.1016/S0140-6736(05)67887-7

[11] Bartelink, H., Horiot, J.C., Poortmans, P.M., Struikmans, H., Van den Bogaert, W., Fourquet, A., et al. (2007) Impact of a Higher Radiation Dose on Local Control and Survival in Breast-Conserving Therapy of Early Breast Cancer: 10 Years Results of the Randomized Boost versus No Boost EORTC 22881-10882 Trial. Journal of Clinical Oncology, 25, 3259-3265. http://dx.doi.org/10.1200/JCO.2007.11.4991

[12] Dubois, J.B., Hay, M., Gely, S., Saint-Aubert, B., Rouanet, P. and Pujol, H. (1997) IORT in Breast Carcinomas. Frontiers of Radiation Therapy and Oncology, 31, 131-137. http://dx.doi.org/10.1159/000061160

[13] Lemanski, C., Azria, D., Gourgon-Bourgade, S., Gutowski, M., Rouanet, P., Saint-Aubert, B., et al. (2010) Intraoperative Radiotherapy in Early-Stage Breast Cancer: Result of the Montpellier Phase II Trial. International Journal of 
Radiation Oncology, Biology, Physics, 76, 698-703. http://dx.doi.org/10.1016/j.ijrobp.2009.02.039

[14] Maffuz, A., Huerta, J. and Rodriguez, S. (2015) Cirugia conservadora y radioterapia intraoperatoria. In: Sanchez, E., Sanchez, C. and Erazo, M., Eds., Cáncer de mama: Actualidades y controversias, Capítulo 29, 259-268.

[15] Florczaka, Z.W., Roszaka, A., Bratosa, K., Milecki, P., Karczewska-Dzionk, A. and Włodarczyka, H. (2013) Intraoperative Radiation Therapy as Part of Breast Conserving Therapy of Early Breast Cancer: Results of One Year Follow-Up. Reports of Practical Oncology \& Radiotherapy, 18, 107-111. http://dx.doi.org/10.1016/j.rpor.2012.10.007

[16] Vaidya, J.S., Baum, M., Tobias, J.S., D’Souza, D.P., Naidu, S.V., Morgan, S., et al. (2001) Targeted Intra-Operative (TARGIT): An Innovative Method of Treatment for Early Breast Cancer. Annals of Oncology, 12, 1075-1080. http://dx.doi.org/10.1023/A:1011609401132

[17] Ohtake, T., Abe, R., Kimijima, I., Fukushima, T., Tsuchiya, A., Hoshi, K., et al. (1995) Intraductal Extension of Primary Invasive Breast Carcinoma Treated by Breast-Conservative Surgery. Cancer, 76, 32-45. http://dx.doi.org/10.1002/1097-0142(19950701)76:1<32::AID-CNCR2820760106>3.0.CO;2-R

[18] Holli, K., Saaristo, R., Isola, J., Joensuu, H. and Hakama, M. (2001) Lumpectomy with or without Postoperative Radiotherapy for Breast Cancer with Favourable Prognostic Features: Results of a Randomized Study. British Journal of Cancer, 84, 164-169. http://dx.doi.org/10.1054/bjoc.2000.1571

[19] Sanghani, M., Truong, P.T., Raad, R.A., Niernierko, A., Lesperance, M., Olibotto, I.A., et al. (2010) Validation of a Web Based Predictive Nomogram for Ipsilateral Breast Tumor Recurrence after Breast Conserving Therapy. Journal of Clinical Oncology, 28, 718-722. http://dx.doi.org/10.1200/JCO.2009.22.6662

[20] Vaidya, J.S., Baum, M., Tobias, J.S., Wenz, F., Massaruts, S., Keshtgar, M., et al. (2010) Targeted Intra-Operative Radiotherapy versus Whole Breast Radiotherapy for Breast Cancer (TARGIT-A Trial): An International, Prospective, Randomized, Non-Inferiority Phase 3 Trial. Lancet, 376, 91-102. http://dx.doi.org/10.1016/S0140-6736(10)60837-9

[21] Shah, C., Wilkinson, J.B., Lanni, T., Jawad, M., Wobb, J., Fowler, A., et al. (2013) Five-Year Outcomes and Toxicities Using 3683-Dimensional Conformal External Beam Radiation Therapy to Deliver Accelerated Partial Breast Irradiation. Clinical Breast Cancer, 13, 206-211. http://dx.doi.org/10.1016/j.clbc.2012.09.020

[22] Leonardi, M.C., Maisonneuve, P., Mastropasqua, M.G., Morra, A., Lazzari, R., Rotmenz, N., et al. (2012) How Do the ASTRO Consensus Statement Guidelines for the Application of Accelerated Partial Breast Irradiation Fit Intraoperative Radiotherapy? A Retrospective Analysis of Patients Treated at the European Institute of Oncology. International Journal of Radiation Oncology, Biology, Physics, 83, 806-813. http://dx.doi.org/10.1016/j.jjrobp.2011.08.014

[23] Vaidya, J.S., Baum, M., Tobias, J.S., Wenz, F., Massarut, S., Keshtgar, M., et al. (2011) Long-Term Results of Targeted Intra-Operative Radiotherapy (TARGIT) Boost during Breast-Conserving Surgery. International Journal of Radiation Oncology, Biology, Physics, 81, 1091-1097. http://dx.doi.org/10.1016/j.ijrobp.2010.07.1996

[24] Vaidya, J.S., Wenz, F., Bulsara, M., Tobias, J.S., Joseph, D.J., Keshtgar, M., et al. (2014) Risk-Adapted Targeted Intraoperative Radiotherapy versus Whole-Breast Radiotherapy for Breast Cancer: 5-Year Results for Local Control and Overall Survival from TARGIT-A Randomized Trial. Lancet, 383, 603-613. http://dx.doi.org/10.1016/S0140-6736(13)61950-9

[25] Polgar, C., Van Limbergen, E., Potter, R., Kivacs, G., Polo, A., Lyczek, J., et al. (2010) Patient Selection for Accelerated Partial-Breast Irradiation (APBI) after Breast-Conserving Surgery: Recommendations of the Groupe European de Curietherapie-European Society for Therapeutic Radiology and Oncology (GEC-ESTRO) Breast Cancer Working Group Based on Clinical Evidence (2009). Radiotherapy and Oncology, 94, 264-273. http://dx.doi.org/10.1016/j.radonc.2010.01.014 